\title{
IMPAIRED DIASTOLIC RECOVERY AFTER ACUTE MYOCARDIAL INFARCTION AS A PREDICTOR OF ADVERSE EVENTS
}

\author{
HYUN JU YOON, MD, KYE HUN KIM, MD, JONG YOON KIM, MD, JAE YOUNG CHO, MD, \\ NAM SIK YOON, MD, HYUNG WOOK PARK, MD, YOUNG JOON HONG, MD, JU HAN KIM, MD, \\ YOUNGKEUN AHN, MD, MYUNG HO JEONG, MD, JEONG GWAN CHO, MD, AND \\ JONG CHUN PARK, MD \\ DEPARTMENT OF CARDIOVASCULAR MEDICINE, CHONNAM NATIONAL UNIVERSITY HOSPITAL, GWANGJU, KOREA
}

BACKGROUND: To investigate the impact of left ventricular (LV) diastolic functional recovery on major adverse cardiac events (MACE) 6 months after acute myocardial infarction (AMI) in patients with preserved LV systolic function.

METHODS: A total 463 patients with preserved LV systolic function at 6 months after an AMI were divided into two groups based on the extent of diastolic recovery assessed by echocardiography: group I $(\mathrm{n}=241)$ showed improving diastolic function and group II ( $\mathrm{n}=222)$ did not. MACE included death, recurrent myocardial infarction, and rehospitalization due to heart failure, and these events were compared with the patients' characteristics at baseline.

RESULTS: Compared with group I, the patients in group II were older and had a higher prevalence of hypertension and diabetes. Blood levels of hemoglobin and triglyceride were lower in group II, whereas the levels of N-terminal pro-B-type natriuretic peptide (NT-proBNP) and of high-sensitivity C-reactive protein were higher in this group than in group I. MACE were significantly more frequent in group II than in group I. Age, elevated NT-proBNP, and impaired diastolic recovery were significant independent predictors of MACE.

CONCLUSION: Despite improvement in LV systolic function, LV diastolic function had not improved in 222 patients (47.9\%) by the 6-month follow-up after the index AMI, and impaired diastolic functional recovery was found to be an independent predictor of MACE. Evaluation of diastolic function would be a useful way to stratify risk in patients discharged after an index AMI.

KEY WORDS: Myocardial infarction · Diastolic function · Prognosis.

\section{INTRODUCTION}

Acute myocardial infarction (AMI) is characterized by myocardial necrosis secondary to prolonged ischemia. Myocardial damage may lead to systolic and diastolic dysfunction, with the subsequent risk of left ventricular (LV) remodeling, neurohormonal activation, and vascular dysfunction. ${ }^{1)}$ Ischemic injury after AMI affects not only systolic but also diastolic LV function. The phenomenon of myocardial stunning has also been shown to have both a systolic and a diastolic component. ${ }^{2)}$ During the ischemic cascade, regional wall motion abnormalities appear early after the reduction in blood flow. ${ }^{3 / 4)}$ Ischemia-induced diastolic dysfunction, or a delay in the onset of regional relaxation, has been demonstrated in the region perfused by the involved coronary artery in both animal and clinical models. ${ }^{5(6)} \mathrm{LV}$ diastolic dysfunction is an earlier, more sensitive sign of myocardial ischemia and persists longer than the systolic disturbance. ${ }^{78)}$ The mechanism of diastolic dysfunction in patients with AMI may involve impaired diastolic relaxation, LV filling, or distensibility of the left ventricle, regardless of whether the LV ejection fraction (LVEF) is normal or abnormal.

For several decades, the recovery of LV systolic dysfunction after AMI and its prognostic implications have been the major focus of research. However, few studies have evaluated the impact of diastolic dysfunction on future clinical outcomes in pa-

- Received: May 22, 2015 •Revised: September 2, 2015 •Accepted: September 2, 2015

- Address for Correspondence: Kye Hun Kim, Department of Cardiovascular Medicine, Chonnam National University Hospital, 42 Jebong-ro, Dong-gu, Gwangju

61469, Korea Tel: +82-62-220-6266, Fax: +82-62-220-6264, E-mail: christiankyehun@hanmail.net

- This is an Open Access article distributed under the terms of the Creative Commons Attribution Non-Commercial License (http://creativecommons.org/licenses/by-nc/3.0)

which permits unrestricted non-commercial use, distribution, and reproduction in any medium, provided the original work is properly cited. 
tients with AMI in whom LV systolic function was preserved based on follow-up echocardiography. Therefore, the purpose of our study was to assess the role of diastolic functional recovery in predicting outcomes in such patients.

\section{METHODS}

\section{STUDY POPULATION}

From August 2007 through July 2011, we identified a total of 2800 patients with AMI who underwent successful percutaneous coronary intervention at our institution. Among these, a total of 463 patients [mean age ( \pm standard deviation) 63.2 $\pm 12.4 \mathrm{yr}$ ] who had preserved LV systolic function (defined as an LVEF greater than $50 \%$ on follow-up echocardiography at 6 months) were included in the final cohort. The patients were divided into two groups based on the presence or absence of diastolic functional recovery on echocardiography at 6 months after the index AMI: group I showed improvement $(\mathrm{n}=241)$ and group II showed no improvement $(n=222)$. Improvement was defined as an increase of $\geq 1$ grade in diastolic function on echocardiography at 6 months, as compared with the initial echocardiographic result. Improvement in the $\mathrm{E} / \mathrm{e}$ ' ratio (early filling/early diastolic mitral annular velocity ratio, as assessed by tissue Doppler imaging) from $\geq 10$ on the baseline echocardiogram to $<10$ at 6-month follow-up was also considered to represent improvement, regardless of diastolic functional grading (see Materials and Methods section). Non-improvement was defined as no change or worsening of diastolic function of $\geq 1$ grade on 6-month follow-up echocardiography, as compared with the initial echocardiogram. The mean ages of groups I and II were $59.4 \pm 12.2$ and $67.3 \pm 11.4$ years, respectively, and there were 191 men in group I and 122 in group II. Major adverse cardiac events (MACE) included death, recurrent myocardial infarction (MI), and rehospitalization due to heart failure and were determined after the 6-month echocardiographic follow-up was completed. The study protocol was approved by the Institutional Review Board at our institution (2010-05-092).

\section{DEFINITIONS OF HYPERTENSION, DIABETES, DYSLIPIDEMIA, MI, AND HEART FAILURE}

Subjects were considered to have hypertension if their blood pressure was $\geq 140 / \geq 90 \mathrm{~mm} \mathrm{Hg}^{9)}$ or if they were being treated for hypertension. The American Diabetes Association criteria $^{10)}$ were used to define diabetes mellitus: fasting plasma glucose levels $\geq 126 \mathrm{mg} / \mathrm{dL}$ on two consecutive assessments or if the patient was being treated for diabetes. Dyslipidemia was diagnosed according to the 2004 update of the NCEP guidelines. ${ }^{11)}$ According to these guidelines, a high level of low-density lipoprotein cholesterol ( $\geq 160 \mathrm{mg} / \mathrm{dL}$ ), a low level of highdensity lipoprotein cholesterol $(\leq 40 \mathrm{mg} / \mathrm{dL})$, and a high level of triglycerides ( $\geq 150 \mathrm{mg} / \mathrm{dL}$ ) were included in our assessment. ${ }^{12)}$

An MI with ST-segment elevation was diagnosed if the pa- tient had continuous chest pain lasting more than 30 minutes, new ST-segment elevation $\geq 2 \mathrm{~mm}$ on at least two contiguous electrocardiographic leads, and a creatine kinase MB fraction (CK-MB) or troponin I (Tn-I) level greater than three times normal values. ${ }^{13)}$ The presence of non-ST-segment elevation MI was diagnosed if the patient had chest pain without new ST-segment elevation and was positive for one of these cardiac biomarkers. ${ }^{14)}$ Infarct-related arteries were identified using a combination of electrocardiographic findings, LV wall motion abnormalities on two-dimensional echocardiography, and coronary angiography.

A positive family history meant early cardiovascular disease in immediate relatives. Clinical demographic features were obtained from a review of hospital records.

\section{LABORATORY TESTS}

Routine laboratory studies were obtained at the time of hospital admission. Cardiac enzymes, including CK-MB and TnI, were checked serially, and the maximal values were used in our data analysis. Blood samples to assess the serum lipid profile and glucose levels were obtained on the morning following admission. High-sensitivity C-reactive protein (hs-CRP) was measured by means of the immunoturbidimetric CRP-Latex (II) high-sensitive assay using an Olympus 5431 autoanalyzer (Olympus America Inc., Melville, NY, USA). Serum N-terminal pro-B-type natriuretic peptide (NT-proBNP) was measured using an electrochemiluminescence sandwich immunoassay method with an Elecsys 2010 analyzer (Roche Diagnostics, Mannheim, Germany), having an analytic range that extended from 5 to $35000 \mathrm{pg} / \mathrm{mL}$. ${ }^{15)}$

\section{ECHOCARDIOGRAPHIC EXAMINATIONS}

Two-dimensional, M-mode, and Doppler echocardiographic examinations were performed (Vivid 7, GE, Milwaukee, WI, USA), with the image point at the time of initial admission (day 1 or 2) and at 6 months after the MI. LV volume and EF were measured using Simpson's formula. ${ }^{16)}$ The LV and left atrial (LA) volume indices were obtained by dividing volume by the body surface area. We used the mean values for three measurements taken by two independent observers of the technically-speaking "best" cardiac cycles from each examination. Intra-observer and inter-observer variabilities with Simpson's method were $4 \pm 5 \%$ and $5 \pm 4 \%$, respectively (absolute difference divided by mean value of measurement).

The wall motion score index (WMSI) was derived for each patient. The left ventricle was divided according to a 17-segment model. ${ }^{17)}$ For each segment, wall motion was scored from 1 (normal) to 4 (dyskinetic). Recordings were stored digitally and analyzed offline with EchoPAC PC software (GE Vingmed Ultrasound, Horten, Norway). All segments were assessed by means of strain rate imaging and wall motion score (WMS) on two-dimensional echocardiography, according to the American Society of Echocardiography guidelines. Because the num- 
ber of infarcted segments per patient varied, WMSI was calculated as the average score for the segments studied in each patient.

Doppler echocardiograms were recorded on a strip chart recorder with a sweep speed of $100 \mathrm{~mm} / \mathrm{s}$. Early transmitral velocity (E wave) was measured by pulsed-wave Doppler from the apical four-chamber view, with the sample volume located at the tip of the mitral leaflets. Early diastolic (e'), late diastolic (a'), and systolic (s') velocities at the septal mitral annulus were obtained in this view by tissue Doppler imaging. LA volumes were measured using the multiple-discs method. ${ }^{18)}$ The maximal LA volume was obtained before mitral valve opening and the minimal volume before valve closure. Volume measurements were averaged over three to five cycles. Diastolic dysfunction was considered normal, grade 1 , grade 2 , or grade 3 according to a multiparametric approach, including the $\mathrm{E} / \mathrm{A}$ ratio, the E/e' ratio, and LA volume based on current guidelines. ${ }^{19}$ An elevated E/e' ratio and increased LA volume are associated with increased LV filling pressures.

\section{STATISTICAL ANALYSIS}

The Statistical Package for Social Sciences for Windows, version 15.0 (SPSS Inc., Chicago, IL, USA) was used for all analyses. For each parameter, the mean, median, and standard deviation were calculated. Statistical significance between means for different groups was calculated by analysis of variance; statistical significance between frequencies was calculated by the chi-square test with Yates' correction or, if the expected value was less than 5, by Fisher's exact test. Relative risks (RR) and confidence intervals $(\mathrm{CI})$ were also calculated. A $p$ value of less than 0.05 was required to reject the null hypothesis. Variables found to be significant on the univariate analyses were entered into the multivariate models.

\section{RESULTS}

\section{BASELINE CLINICAL CHARACTERISTICS}

Table 1 summarizes the baseline clinical characteristics for

Table 1. Baseline clinical characteristics of patients in group I (improving) and group II (non-improving)

\begin{tabular}{lccr}
\hline & Improving group $(\mathrm{n}=241)$ & Non-improving group $(\mathrm{n}=222)$ & $p$ value \\
\hline Age $(\mathrm{yr})$ & $59.4 \pm 12.2$ & $67.3 \pm 11.4$ & $<0.001$ \\
Male $(\%)$ & 79.3 & 54.9 & $<0.001$ \\
Weight $(\mathrm{kg})$ & $64.5 \pm 10.8$ & $64.7 \pm 12.0$ & 0.781 \\
Height $(\mathrm{cm})$ & $163.5 \pm 8.3$ & $162.1 \pm 9.7$ & 0.103 \\
BMI $\left(\mathrm{kg} / \mathrm{m}^{2}\right)$ & $24.0 \pm 2.9$ & $24.5 \pm 3.2$ & 0.091 \\
Hypertension $(\%)$ & 41.5 & 62.6 & $<0.001$ \\
Diabetes $(\%)$ & 22.2 & 36.9 & $<0.001$ \\
Smoking $(\%)$ & 15.7 & 15.7 & 0.587 \\
Family history $(\%)$ & 8.3 & 4.5 & 0.070 \\
SBP $(\mathrm{mm}$ Hg) & $129.1 \pm 32.1$ & $128.7 \pm 32.3$ & 0.889 \\
DBP $(\mathrm{mm} \mathrm{Hg})$ & $83.7 \pm 53.4$ & $79.8 \pm 19.5$ & 0.311 \\
Heart rate $(\mathrm{bpm})$ & $74.7 \pm 19.2$ & $77.4 \pm 20.1$ & 0.142 \\
Killip class $\geq \mathrm{II}(\%)$ & 55.6 & 65.9 & $<0.001$ \\
STEMI $(\%)$ & 60.4 & 51.6 & 0.062 \\
\hline
\end{tabular}

BMI: body mass index, SBP: systolic blood pressure, DBP: diastolic blood pressure, STEMI: ST-segment elevation myocardial infarction

Table 2. Prescribed medications in groups I and II

\begin{tabular}{lccc}
\hline & Improving group $(\mathrm{n}=241)$ & Non-improving group $(\mathrm{n}=222)$ & $p$ value \\
\hline Aspirin (\%) & 99.6 & 100 & 0.285 \\
Clopidogrel (\%) & 98.7 & 98.6 & 0.618 \\
Cilostazol (\%) & 58.8 & 51.6 & 0.136 \\
Beta blocker (\%) & 88.1 & 86.0 & 0.675 \\
ACEI (\%) & 55.8 & 56.4 & 0.549 \\
ARB (\%) & 38.5 & 37.2 & 0.775 \\
CCB (\%) & 6.19 & 10.1 & 0.091 \\
Diuretics (\%) & 20.6 & 33.3 & 0.007 \\
Nitrate (\%) & 68.4 & 73.4 & 0.322 \\
Inotropic agents (\%) & 28.9 & 28.5 & 0.921 \\
Statin (\%) & 90.2 & 89.1 & 0.701 \\
\hline
\end{tabular}

ACEI: angiotensin-converting enzyme inhibiter, ARB: angiotensin II-receptor blocker, CCB: calcium-channel blocker 
groups I and II. Patients in group II were older and included more women than the patients in group I, and hypertension and diabetes were more prevalent in group II. Prescribed medications did not differ between the groups except for the more frequent use of diuretics in group II (Table 2).

\section{LABORATORY, ECHOCARDIOGRAPHIC, AND CORONARY ANGIOGRAPHIC FINDINGS}

Table 3 summarizes the laboratory findings. Initial hemoglobin and triglyceride levels were lower, whereas the levels of NTproBNP and hs-CRP were higher in group II than in group I. Echocardiographic findings are summarized in Table 4. The parameters used to assess diastolic function, such as LA size, LA volume, e', E/e', and E/e' at 6 months, were significantly more impaired in group II than in group I. Coronary angiographic findings, summarized in Table 5, showed no significant differences between the groups.

\section{CLINICAL OUTCOMES}

During the follow-up period (mean $910 \pm 750$ days), MACE occurred in 124 patients (31 deaths, 12 recurrent MIs, and 81 rehospitalizations due to heart failure) and were significantly more frequent in group II than in group I ( 76 vs. 48 , respectively) $(p=0.001)$ (Fig. 1). Significantly more deaths occurred in group II than in group I ( 24 vs. 7 , respectively) $(p=0.001)$, but the number of patients with recurrent MI ( 4 in group I vs. 8 in group II) as well as the number requiring rehospitalization ( 38 in group I vs. 43 in group II) did not differ significantly be-

Table 3. Laboratory findings in groups I (improving) and II (non-improving)

\begin{tabular}{|c|c|c|c|}
\hline & Improving group $(\mathrm{n}=241)$ & Non-improving group $(\mathrm{n}=222)$ & $p$ value \\
\hline WBC (mg/dL) & $7277 \pm 2287$ & $7664 \pm 2310$ & 0.067 \\
\hline Hemoglobin $(\mathrm{g} / \mathrm{dL})$ & $13.3 \pm 2.1$ & $12.8 \pm 2.4$ & 0.018 \\
\hline Glucose (g/dL) & $178.0 \pm 94$ & $178.1 \pm 90$ & 0.990 \\
\hline Creatinine $(\mathrm{mg} / \mathrm{dL})$ & $1.01 \pm 0.6$ & $1.03 \pm 0.6$ & 0.812 \\
\hline $\mathrm{TC}(\mathrm{mg} / \mathrm{dL})$ & $183.4 \pm 38.5$ & $181.9 \pm 40.7$ & 0.673 \\
\hline $\mathrm{TG}(\mathrm{mg} / \mathrm{dL})$ & $130.9 \pm 99.9$ & $115.4 \pm 61.0$ & 0.049 \\
\hline $\mathrm{LDL}-\mathrm{C}(\mathrm{mg} / \mathrm{dL})$ & $119.5 \pm 39.8$ & $118.9 \pm 37.4$ & 0.883 \\
\hline HDL-C (mg/dL) & $45.5 \pm 12.2$ & $43.9 \pm 12.3$ & 0.191 \\
\hline CK-MB (ng/mL) & $69.9 \pm 16.8$ & $69.9 \pm 123.6$ & 0.668 \\
\hline Tn-I (ng/mL) & $38.7 \pm 41.7$ & $47.1 \pm 60.0$ & 0.252 \\
\hline NT-proBNP (pg/mL) & $1787 \pm 4122$ & $5258 \pm 8818$ & $<0.001$ \\
\hline hs-CRP (mg/dL) & $1.55 \pm 2.3$ & $2.20 \pm 3.8$ & 0.038 \\
\hline $\operatorname{HbA1c}(\%)$ & $6.54 \pm 1.5$ & $6.64 \pm 1.4$ & 0.502 \\
\hline
\end{tabular}

WBC: white blood cell count, TC: total cholesterol, TG: triglyceride, LDL-C: low-density lipoprotein cholesterol, HDL-C: high-density lipoprotein cholesterol, CK-MB: MB fraction of creatinine kinase, Tn-I: troponin I, NT-proBNP: N-terminal pro-B-type natriuretic peptide, hs-CRP: high-sensitivity C-reactive protein, HbA1c: glycosylated hemoglobin

Table 4. Echocardiographic findings in groups I and II

\begin{tabular}{lccr}
\hline & Improving group $(\mathrm{n}=241)$ & Non-improving group $(\mathrm{n}=222)$ & $p$ value \\
\hline LVEDV $(\mathrm{mL})$ & $160.8 \pm 54.6$ & $165.5 \pm 57.6$ & 0.160 \\
LVESV $(\mathrm{mL})$ & $72.4 \pm 35.1$ & $76.8 \pm 31.5$ & 0.375 \\
Initial EF (\%) & $56.3 \pm 11.9$ & $54.5 \pm 12.1$ & 0.100 \\
Follow-up EF $(\%)$ & $61.4 \pm 6.8$ & $60.1 \pm 7.0$ & 0.051 \\
LAD (mm) & $36.5 \pm 5.3$ & $39.7 \pm 5.8$ & $<0.001$ \\
LAVI (mL/m $\left.{ }^{2}\right)$ & $52.8 \pm 17.1$ & $63.8 \pm 21.2$ & $<0.001$ \\
Initial WMS & $21.2 \pm 4.9$ & $21.7 \pm 5.1$ & 0.253 \\
Follow-up WMS & $18.8 \pm 3.8$ & $18.8 \pm 3.9$ & 0.890 \\
E (cm/sec) & $0.64 \pm 0.21$ & $0.74 \pm 0.26$ & $<0.001$ \\
A (cm/sec) & $0.76 \pm 0.18$ & $0.83 \pm 0.25$ & 0.010 \\
e' (cm/sec) & $0.065 \pm 0.02$ & $0.058 \pm 0.02$ & 0.013 \\
Initial E/e' ratio & $10.97 \pm 4.95$ & $14.37 \pm 7.06$ & $<0.001$ \\
Follow-up E/e' ratio & $11.5 \pm 1.80$ & $15.4 \pm 6.44$ & $<0.001$ \\
\hline
\end{tabular}

LVEDV: left ventricular end-diastolic volume, LVESV: left ventricular end-systolic volume, EF: ejection fraction, LAD: left atrial dimension, LAVI: left atrial volume index, WMS: wall motion score, E: early diastolic mitral inflow velocity, A: late diastolic mitral inflow velocity, DT: deceleration time, e': early diastolic velocity of mitral septal annulus 
Table 5. Coronary angiographic findings in groups I and II

\begin{tabular}{lccc}
\hline & Improving group $(\mathrm{n}=241)$ & Non-improving group $(\mathrm{n}=222)$ & $p$ value \\
\hline Infarct-related artery & & & 0.154 \\
LAD (\%) & 50.4 & 40.1 & 20.3 \\
RCA (\%) & 13.3 & 34.4 & 1.51 \\
LCX (\%) & 34.2 & 55.4 & 0.461 \\
Left main (\%) & 0.42 & & 0.788 \\
Multivessel disease (\%) & 45.5 & 70.1 & 1.182 \\
TIMI flow grade $<3$ & & 0.0 & \\
Pre-PCI (\%) & 68.8 & 0.0 & \\
Post-PCI (\%) & & & \\
\hline
\end{tabular}

LAD: left anterior descending coronary artery, RCA: right coronary artery, LCX: left circumflex coronary artery, TIMI: Thrombolysis in Myocardial Infarction, PCI: percutaneous coronary intervention

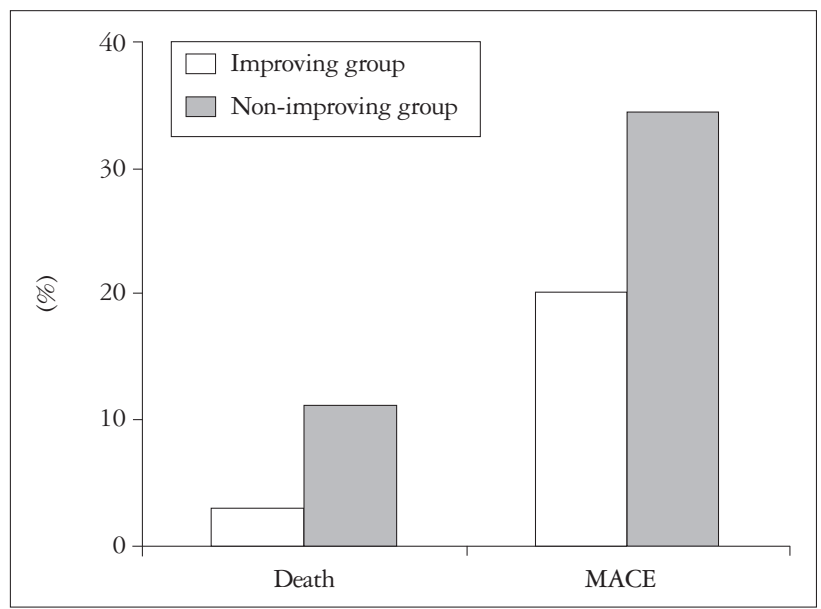

Fig. 1. Comparison of deaths and major adverse cardiac events (MACE) between group I (improving) and group II (non-improving).

tween groups I and IIII, 38. Cumulative survival and MACEfree survival rates were significantly lower in group II than in group I on Kaplan-Meier analysis (Fig. 2).

To identify independent predictors of mortality, we conducted a multivariate regression analysis using the variables of mortality found to be significant on univariate analysis. As shown in Table 6, age $(\mathrm{RR}=1.089, \mathrm{CI}=1.044-1.136, p=$ 0.017), elevated NT-proBNP $(\mathrm{RR}=3.958, \mathrm{CI}=1.841-8.512$, $p<0.001)$, and impaired diastolic functional recovery $(\mathrm{RR}=$ $1.629, \mathrm{CI}=1.041-2.550, p=0.033)$ were significant independent predictors of long-term mortality.

\section{DISCUSSION}

The two main findings of this study are as follows:

1) Despite the recovery of $L V$ systolic function after the index AMI, LV diastolic function had not improved by the 6-month follow-up in a significant proportion of patients.

2) Impaired diastolic functional recovery was an independent predictor of MACE after AMI.

AMI causes acute derangement of myocardial contraction and relaxation mechanics. In the case of myocardial ischemia, diastolic dysfunction often precedes systolic dysfunction. To overcome these abnormal changes, the myocardial repair process is activated immediately after an index AMI, and these dynamic processes are regulated by a number of cytokines and neurohormones to prevent progressive dilation of the left ventricle. ${ }^{2021)}$ Various factors such as interstitial edema, fibrocellular infiltration, and scar formation will also affect LV chamber stiffness, ${ }^{2223)}$ so many patients with AMI have a period of advanced diastolic dysfunction, as well as systolic dysfunction, after the acute episode.

Although acute diastolic and systolic dysfunction after AMI may improve with the successful restoration of coronary blood flow by means of a percutaneous coronary intervention, some patients show persistence or aggravation of systolic or diastolic functional abnormalities accompanied by chamber dilatation, so-called ventricular remodeling. ${ }^{24)}$ Previous studies have shown that the persistent restrictive filling pattern at discharge may induce severe alterations in LV geometry or function, with a high risk for remodeling at 6 months, ${ }^{25)}$ but the impact on clinical outcomes of impaired diastolic recovery during follow-up has been insufficiently evaluated.

In our study, diastolic function either did not improve or deteriorated in about a half the patients with AMI even though systolic function was found to be improved on echocardiographic follow-up at 6 months, and this persistent diastolic dysfunction was a significant predictor of long-term MACE. Therefore, our results suggest that serial monitoring of diastolic function would be useful in the risk stratification of patients with AMI, regardless of systolic functional status.

Diastolic function as evaluated on Doppler ultrasound provides important prognostic information that supplements information about systolic function. ${ }^{2627)}$ A previous meta-analysis of results from several prospective postinfarction clinical trials revealed that $20 \%$ of a large cohort of patients with AMI had restricted LV filling. ${ }^{28)}$ Diastolic function was reversible, especially in patients with grade 3 and grade 4 diastolic dysfunction. However, Doppler variables can change rapidly and are affected by factors such as the patient's age, heart rate, and LV 


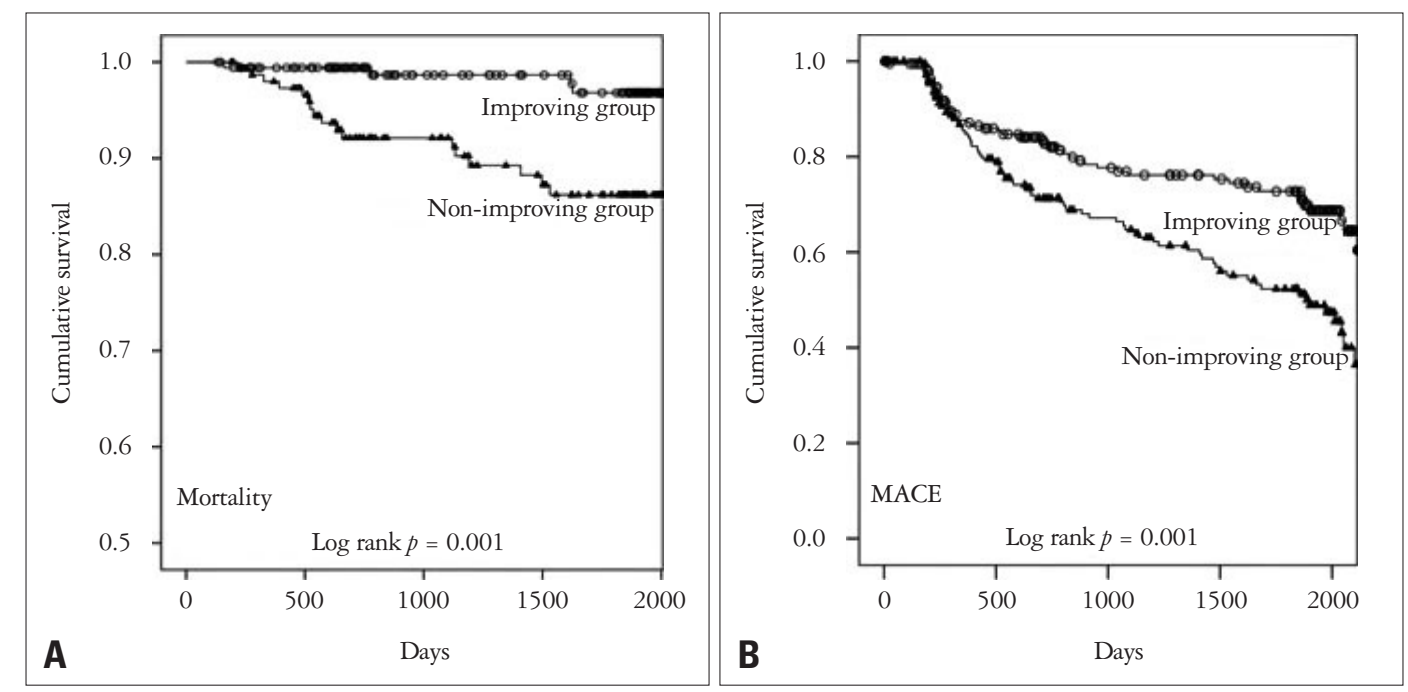

Fig. 2. Kaplan-Meier curve analyses of cumulative survival (A) and of major adverse cardiac events (MACE) (B) in group I (improving) and group II (non-improving).

\begin{tabular}{lccr}
\multicolumn{4}{l}{ Table 6. Predictors of mortality on multivariate analysis } \\
\hline & RR & CI & $p$ value \\
\hline Age & 1.089 & $1.044-1.136$ & 0.017 \\
Gender (male) & 0.854 & $0.386-1.888$ & 0.697 \\
Hypertension & 1.422 & $0.626-3.228$ & 0.458 \\
Diabetes & 1.363 & $0.602-3.228$ & 0.453 \\
Killip class $\geq$ II & 1.651 & $0.606-4.504$ & 0.327 \\
Impaired diastolic recovery & 1.629 & $1.041-2.550$ & 0.033 \\
Left atrial volume & 0.999 & $0.990-1.008$ & 0.821 \\
E/e' ratio & 1.027 & $0.986-1.070$ & 0.204 \\
Follow-up E/e' ratio & 1.054 & $1.008-1.089$ & 0.017 \\
Hemoglobin level & 1.025 & $0.926-1.135$ & 0.635 \\
Triglyceride level & 0.998 & $0.994-1.002$ & 0.182 \\
NT-proBNP (log) & 3.958 & $1.841-8.512$ & $<0.001$ \\
hs-CRP level & 1.049 & $0.935-1.078$ & 0.360 \\
Diuretic use & 1.182 & $0.639-2.208$ & 0.586 \\
\hline
\end{tabular}

RR: relative risk, CI: confidence interval, E: early diastolic mitral inflow velocity, e': early diastolic velocity of mitral septal annulus, NT-proBNP: Nterminal pro-B-type natriuretic peptide, hs-CRP: high-sensitivity C-reactive protein

loading conditions, which explains why evaluating diastolic function with Doppler parameters alone is not sufficient. Because LA volume is less influenced by acute changes and reflects subacute or chronic diastolic function, it may be more reasonable to include LA volume status when assessing diastolic function in patients with AMI. ${ }^{29)}$ In this study, we defined "improvement" in terms of grade of diastolic dysfunction and a decrease in the E/e' ratio to less than 10 at 6-month follow-up echocardiography, because patients with AMI reach a relatively steady state during this period of time.

The timing of echocardiography after infarction is critical in that LV chamber and myocardial stiffness may fluctuate before and after the repair process gets under way. The LV end-systol- ic volume index, LVEF, infarct size, and progressive ventricular remodeling are known to be predictors of clinical outcome after AMI. Although, as previously mentioned, risk stratification after AMI is often focused on LV systolic function, it appears that a more complete study of ventricular function that includes an assessment of LV diastolic function would be useful. In addition, significant LV diastolic dysfunction might persist despite an improvement in LV systolic function. Sustained LV diastolic dysfunction may have a significant impact on exercise capacity and long-term outcomes in patients treated with cardiac resynchronization therapy. ${ }^{30)}$ The results of our study indicate that patients in whom persistent diastolic dysfunction persists after an AMI have a worse prognosis than patients whose diastolic function has recovered. Moreover, the prognostic information provided by a diastolic assessment is independent of that derived from an evaluation of systolic function alone.

There are several limitations in the present study. First, it is a retrospective observational study. Second, we did not consider the possible effects of risk factor modification that might influence clinical outcomes. Studies with longer follow-up periods are needed to determine such effects. Third, several factors that were not taken into account in the current analysis, such as coexisting illnesses, could also have affected LV diastolic function.

In conclusion, we found that the failure to recover LV diastolic function is not uncommon after AMI despite LV systolic functional recovery, and impaired diastolic function 6 months after an index AMI is a significant predictor of long-term clinical outcomes such as MACE. Therefore, serial monitoring of diastolic function over a period of at least 6 months would be useful in predicting future clinical adverse events in patients with AMI.

- Acknowledgements

The current study was supported by a research grant from the Korean Society of Echocardiography. 


\section{REFERENCES}

1. Møller JE, Pellikka PA, Hillis GS, Oh JK. Prognostic importance of diastolic function and filling pressure in patients with acute myocardial infarction. Circulation 2006;114:438-44.

2. Nesto RW, Kowalchuk GJ. The ischemic cascade: temporal sequence of bemodynamic, electrocardiographic and symptomatic expressions of ischemia. Am J Cardiol 1987;59:23C-30C.

3. St John Sutton M, Pfeffer MA, Plappert T, Rouleau JL, Moyé LA, Dagenais GR, Lamas GA, Klein M, Sussex B, Goldman S, Menapace FJ, Parker JO, Lewis S, Sestier F, Gordon DF, McEwan P, Bernstein V, Braunwald E. Quantitative two-dimensional echocardiographic measurements are major predictors of adverse cardiovascular events after acute myocardial infarction. The protective effects of captopril. Circulation 1994; 89:68-75.

4. Grigioni F, Enriquez-Sarano M, Zehr KJ, Bailey KR, Tajik AJ. Ischemic mitral regurgitation: long-term outcome and prognostic implications with quantitative Doppler assessment. Circulation 2001;103:1759-64.

5. St John Sutton M, Lee D, Rouleau JL, Goldman S, Plappert T, Braunwald E, Pfeffer MA. Left ventricular remodeling and ventricular arrhythmias after myocardial infarction. Circulation 2003;107:2577-82.

6. Zhang Z, Friedman D, Dione DP, Lin BA, Duncan JS, Sinusas AJ, Sampath S. Assessment of left ventricular 2D flow pathlines during early diastole using spatial modulation of magnetization with polarity alternating velocity encoding: a study in normal volunteers and canine animals with myocardial infarction. Magn Reson Med 2013;70:766-75.

7. Cavalcante JL, Marwick TH, Hachamovitch R, Popovic ZB, Aldweib N, Starling RC, Desai MY, Flamm SD, Kwon DH. Is there a role for diastolic function assessment in era of delayed enbancement cardiac magnetic resonance imaging?: a multimodality imaging study in patients with advanced ischemic cardiomyopathy. Am Heart J 2014;168:220-8.e1.

8. Hillis GS, Møller JE, Pellikka PA, Gersh BJ, Wright RS, Ommen SR, Reeder GS, Oh JK. Noninvasive estimation of left ventricular filling pressure by E/e' is a powerful predictor of survival after acute myocardial infarction. J Am Coll Cardiol 2004;43:360-7.

9. Chobanian AV, Bakris GL, Black HR, Cushman WC, Green LA, Izzo JL Jr, Jones DW, Materson BJ, Oparil S, Wright JT Jr, Roccella EJ; National Heart, Lung, and Blood Institute Joint National Committee on Prevention, Detection, Evaluation, and Treatment of High Blood Pressure; National High Blood Pressure Education Program Coordinating Committee. The Seventh Report of the Joint National Committee on Prevention, Detection, Evaluation, and Treatment of High Blood Pressure: the JNC 7 report. JAMA 2003;289:2560-72.

10. Report of the Expert Committee on the Diagnosis and Classification of Diabetes Mellitus. Diabetes Care 1997;20:1183-97.

11. Grundy SM, Cleeman JI, Merz CN, Brewer HB Jr, Clark LT, Hunninghake DB, Pasternak RC, Smith SC Jr, Stone NJ; National Heart, Lung, and Blood Institute; American College of Cardiology Foundation; American Heart Association. Implications of recent clinical trials for the National Cholesterol Education Program Adult Treatment Panel III guidelines. Circulation 2004;110:227-39.

12. Hatzitolios AI, Athyros VG, Karagiannis A, Savopoulos C, Charalambous C, Kyriakidis G, Milidis T, Papathanakis C, Bitli A, Vogiatsis I, Ntaios G, Katsiki N, Symeonidis A, Tziomalos K, Mikhailidis DP; IMPROVE Collaborative Group. Implementation of strategy for the management of overt dyslipidemia: the IMPROVE-dyslipidemia study. Int J Cardiol 2009;134:322-9.

13. O'Gara PT, Kushner FG, Ascheim DD, Casey DE Jr, Chung MK, de Lemos JA, Ettinger SM, Fang JC, Fesmire FM, Franklin BA, Granger CB, Krumholz HM, Linderbaum JA, Morrow DA, Newby LK, Ornato JP, Ou N, Radford MJ, Tamis-Holland JE, Tommaso JE, Tracy CM, Woo YJ, Zhao DX; CF/AHA Task Force. 2013 ACCF/ AHA guideline for the management of ST-elevation myocardial infarction: executive summary: a report of the American College of Cardiology Foundation/American Heart Association Task Force on Practice Guidelines. Circulation 2013;127:529-55.

14. Wright RS, Anderson JL, Adams CD, Bridges CR, Casey DE Jr, Ettinger SM, Fesmire FM, Ganiats TG, Jneid H, Lincoff AM, Peterson ED, Philippides GJ, Theroux P, Wenger NK, Zidar JP, Anderson JL, Adams CD, Antman EM, Bridges CR, Califf RM, Casey DE Jr, Chavey WE 2nd, Fesmire FM, Hochman JS, Levin TN, Lincoff AM, Peterson ED, Theroux P, Wenger NK, Zidar JP; American College of Cardiology Foundation/American Heart Association Task Force on Practice Guidelines. 2011 ACCF/AHA focused update incorporated into the ACC/AHA 2007 Guidelines for the Management of Patients with Unstable Angina/Non-ST-Elevation Myocardial Infarction: a report of the American College of Cardiology Foundation/American Heart Association Task Force on Practice Guidelines developed in collaboration with the American Academy of Family Physicians, Society for Cardiovascular Angiography and Interventions, and the Society of Thoracic Surgeons. J Am Coll Cardiol 2011;57:e215-367.

15. Luchner A, Behrens G, Stritzke J, Markus M, Stark K, Peters A, Meisinger C, Leitzmann M, Hense HW, Schunkert H, Heid IM. Longterm pattern of brain natriuretic peptide and $N$-terminal pro brain natriuretic peptide and its determinants in the general population: contribution of age, gender, and cardiac and extra-cardiac factors. Eur J Heart Fail 2013; 15:859-67.

16. Simonson JS, Schiller NB. Descent of the base of the left ventricle: an echocardiographic index of left ventricular function. J Am Soc Echocardiogr 1989; 2:25-35.

17. Cerqueira MD, Weissman NJ, Dilsizian V, Jacobs AK, Kaul S, Laskey WK, Pennell DJ, Rumberger JA, Ryan T, Verani MS; American Heart Association Writing Group on Myocardial Segmentation and Registration for Cardiac Imaging. Standardized myocardial segmentation and nomenclature for tomographic imaging of the heart. A statement for healthcare professionals from the Cardiac Imaging Committee of the Council on Clinical Cardiology of the American Heart Association. Circulation 2002;105:539-42.

18. Appleton CP, Galloway JM, Gonzalez MS, Gaballa M, Basnight MA. Estimation of left ventricular filling pressures using two-dimensional and Doppler echocardiography in adult patients with cardiac disease. Additional value of analyzing left atrial size, left atrial ejection fraction and the difference in duration of pulmonary venous and mitral flow velocity at atrial contraction. J Am Coll Cardiol 1993;22:1972-82.

19. Nagueh SF, Appleton CP, Gillebert TC, Marino PN, Oh JK, Smiseth OA, Waggoner AD, Flachskampf FA, Pellikka PA, Evangelista A. Recommendations for the evaluation of left ventricular diastolic function by echocardiography. J Am Soc Echocardiogr 2009;22:107-33.

20. French BA, Kramer CM. Mechanisms of Post-Infarct Left Ventricular Remodeling. Drug Discov Today Dis Mech 2007;4:185-96.

21. Eghbali M, Weber KT. Collagen and the myocardium: fibrillar structure, biosynthesis and degradation in relation to hypertrophy and its regression. Mol Cell Biochem 1990;96:1-14.

22. Cleutjens JP, Blankesteijn WM, Daemen MJ, Smits JF. The infarcted myocardium: simply dead tissue, or a lively target for therapeutic interventions. Cardiovasc Res 1999;44:232-41.

23. Wijns W, Serruys PW, Slager CJ, Grimm J, Krayenbuehl HP, Hugenholtz PG, Hess OM. Effect of coronary occlusion during percutaneous transluminal angioplasty in humans on left ventricular chamber stiffness and regional diastolic pressure-radius relations. J Am Coll Cardiol 1986;7: 455-63.

24. Yoon HJ, Jeong MH, Bae JH, Kim KH, Ahn Y, Cho JG, Park JC, Kang JC. Dyslipidemia, low left ventricular ejection fraction and high wall motion score index are predictors of progressive left ventricular dilatation after acute myocardial infarction. Korean Circ J 2011;41:124-9. 
25. Blomstrand P, Engvall M, Festin K, Lindström T, Länne T, Maret E, Nyström FH, Maret-Ouda J, Östgren CJ, Engvall J. Left ventricular diastolic function, assessed by echocardiography and tissue Doppler imaging, is a strong predictor of cardiovascular events, superior to global left ventricular longitudinal strain, in patients with type 2 diabetes. Eur Heart J Cardiovasc Imaging 2015 Mar 6. pii: jev027. (Epub ahead of print)

26. Fontes-Carvalho R, Sampaio F, Teixeira M, Rocha-Gonçalves F, Gama V, Azevedo A, Leite-Moreira A. Left ventricular diastolic dysfunction and E/E' ratio as the strongest echocardiographic predictors of reduced exercise capacity after acute myocardial infarction. Clin Cardiol 2015;38:222-9.

27. Møller JE, Søndergaard E, Seward JB, Appleton CP, Egstrup K. Ratio of left ventricular peak E-wave velocity to flow propagation velocity assessed by color M-mode Doppler echocardiography in first myocardial infarction: prognostic and clinical implications. J Am Coll Cardiol 2000;35:363-70.
28. Whalley GA, Gamble GD, Doughty RN. Restrictive diastolic filling predicts death after acute myocardial infarction: systemic review and metaanalysis of prospective studies. Heart 2006;92:1588-94.

29. Yoon HJ, Jeong MH, Jeong Y, Kim KH, Song JE, Cho JY, Jang SY, Jeong HC, Lee KH, Park KH, Sim DS, Yoon NS, Hong YJ, Park HW, Kim JH, Ahn Y, Cho JG, Park JC, Kang JC. Progressive dilation of the left atrium and ventricle after acute myocardial infarction is associated with high mortality. Korean Circ J 2013;43:731-8.

30. Fantoni C, Regoli F, Ghanem A, Raffa S, Klersy C, Sorgente A, Faletra F, Baravelli M, Inglese L, Salerno-Uriarte JA, Klein HU, Moccetti T, Auricchio A. Long-term outcome in diabetic heart failure patients treated with cardiac resynchronization therapy. Eur J Heart Fail 2008;10:298307. 